DR. JENNY SIM (Orcid ID : 0000-0001-6863-0541)

PROF. ELIZABETH JANE HALCOMB (Orcid ID : 0000-0001-8099-986X)

Article type : Original Article

\title{
Measuring the outcomes of nursing practice: A Delphi study
}

\author{
Jenny Sim RN, BSc(Nurs), Grad Dip (Bus), Grad Dip (Nurs), PhD, MACN \\ Senior Lecturer, \\ School of Nursing \\ University of Wollongong \\ Northfields Ave Wollongong NSW 2522, Australia \\ P: +612 44291551 | F: +612 44291556 | E: jennysim @uow.edu.au
}

Professor Patrick Crookes RN, RNT, BSc(Nursing), Cert Ed, PhD, MRCN, PFHEA National Head,

School of Nursing, Midwifery \& Paramedicine, Australian Catholic University

PO Box 968, North Sydney NSW 2059, Australia

P: +61 294659156 | M: 0408973219 | E: Patrick.Crookes@acu.edu.au

Professor Kenneth Walsh RPN, RGN, BNurs, PhD, Fellow JBI

Professor of Translational Research in Nursing \& Midwifery

School of Health Sciences

University of Tasmania

Locked Bag 135, Hobart TAS 7001, Australia

P: +61 362267375 | F: +61 362264690 | E: Kenneth.Walsh@utas.edu.au

Professor Elizabeth HALCOMB RN BN(Hons) PhD FACN

Professor of Primary Health Care Nursing

School of Nursing

University of Wollongong

Northfields Ave Wollongong NSW 2522, Australia

P: +612 42213784 | F: +612 42213137 | E: ehalcomb @uow.edu.au

This article has been accepted for publication and undergone full peer review but has not been through the copyediting, typesetting, pagination and proofreading process, which may lead to differences between this version and the Version of Record. Please cite this article as doi: 10.1111/jocn.13971

This article is protected by copyright. All rights reserved. 
Corresponding author:

Jenny Sim

School of Nursing

University of Wollongong

Northfields Ave Wollongong NSW 2522, Australia

P: +612 44291551 | F: +612 44291556 | E: jennysim@uow.edu.au

\section{Measuring the outcomes of nursing practice: A Delphi study}

\section{Abstract}

Aim. To develop nursing-sensitive patient indicators to measure the outcomes of nursing practice.

Background. Nurses play an important role in the health care system yet there is no consensus on how the impact of nursing work should be evaluated. Limited research has previously examined the views of clinical nurses on the important concepts for measuring nursing practice.

Design. A four-round modified Delphi survey sought opinions from patients and nurses about the relevant concepts and their relative priority as indicators of quality nursing practice.

Method. Round 1 comprised semi-structured interviews with patients and nurses to identify key concepts. Nurses were then asked to participate in three rounds of Delphi survey to identify and rate key concepts from which indicators were developed. Thematic analysis and descriptive statistics were used to analyse the data. 
Results. By the end of Round 4, the process had generated 103 concepts and participants had agreed on 8 overarching constructs, namely: care and caring; communication; coordination and collaboration; safety; patient characteristics; workload; Nurses work environment; and organisational characteristics.

Conclusions. Consensus was achieved between nurses on the most important concepts which can provide the basis for measuring the quality and safety of nursing practice in a comprehensive and holistic way.

Relevance to clinical practice. The identification of concepts that patients and nurses consider important for measuring nursing practice will guide the development of methods for evaluating nursing in the future. Ensuring that nursing practice is rigorously evaluated has the potential to identify opportunities to improve nursing quality, patient safety and improve health outcomes.

Keywords: quality, safety, patient outcomes, nursing-sensitive outcomes, nursingsensitive indicators, Delphi technique

\section{What does this paper contribute to the wider global clinical community?}

- The 103 concepts and 8 constructs identified by this study provide the basis for evaluating the safety and quality of nursing practice.

- The constructs of care and caring, communication, and coordination and collaboration provide important information about the actions of nurses and the outcomes of their work. The aforementioned constructs can be used to complement the construct of safety to evaluate nursing practice.

This article is protected by copyright. All rights reserved. 
- Measuring nursing outcomes has the potential to support and improve nursing in all areas of practice. Evaluation of nursing practice in a comprehensive way can facilitate improvements in nursing quality, patient safety, the patient experience of care and health care outcomes.

\section{INTRODUCTION}

Measuring nursing practice is challenging. Nurses practice in a variety of roles and clinical settings, working with other health care professionals to deliver health care to patients. Despite attempts to measure nursing practice commencing with Florence Nightingale (Marek 1998), there has been no agreement within the nursing profession on how the quality of nursing care should be measured. Similarly, there is no agreed set of indicators or performance measures that comprehensively capture the unique contribution that nursing makes to patient outcomes. This does not mean that there have not been attempts to measure the outcomes of nursing practice. On the contrary, a large volume of literature has been published on this topic. Various sets of indicators have been developed, including the National Quality Forum (NQF) set of endorsed Nursing-Sensitive Care Performance measures (Kurtzman \& Corrigan 2007), the NDNQI indicator set (Press Ganey 2017) and the CALNOC database (CALNOC 2017). However, these indicators do not measure the impact of nursing practice in a comprehensive way. In addition a plethora of empirical studies have examined nursing outcomes (for example: Griffiths et al. 2016, Twigg et al. 2016). Most of these studies examine only limited aspects of care, such as safety and nurse staffing (for example: Unruh \& Zhang 2012). 


\section{BACKGROUND}

Research which examines the contributions that nursing makes to patient outcomes is usually referred to by the term nursing-sensitive (patient) outcomes (NSPO) or nursing-sensitive (patient) indicators (NSPI) (Doran 2003). These terms are often used interchangeably and for simplicity, the term NSPO will be used in this paper. The term nursing-sensitive refers to the notion that nurses and nursing care are not wholly responsible for the patient outcome being examined, but rather, that nurse's contribution to the outcome is significant and measureable. Doran (2003) describes NSPOs as 'those that are relevant, based on nurses' scope and domain of practice and for which there is empirical evidence linking nursing inputs and intervention to the outcomes" [for patients] (p. viii).

There are a variety of methods for exploring NSPOs. In the USA, datasets such as NDNQI or CALNOC are used by many organisations to collect unit level data from hospitals for analysis, benchmarking and feedback (CALNOC 2017, Press Ganey 2017). Cross-sectional surveys are also used to gather data on the impact of nursing care using a variety of instruments and foci (Sermeus et al. 2011). Nurse metrics have been developed in some organisations or specialty groups to collect agreed indicators (Maben et al. 2012). Nursing minimum data sets and electronic health care records have also enabled the development of systems of nomenclature such as the International Classification of Nursing Practice (ICNP) (International Council of Nurses (ICN) 2009) or the Nursing Intervention Classification and Nursing Outcomes classification that complements the North American Nursing Diagnosis Association (NANDA) diagnostic codes (Maas et al. 1996). Data abstraction from large administrative data sets and coded medical records is also frequently used in NSPO research (Needleman et al. 2002). Each of these methods have their relative 
advantages and disadvantages and have evolved over time based upon data availability (Clarke 2009, Doran 2003)(Authors own). The variety of methods used in NSPO research, however, illustrates that there is no clear and agreed right way to measure the unique contribution that nurses make to patient outcomes.

Most NSPOs (for example: falls, pressure injuries, mortality) are focused on patient safety and the linkages between quantity and quality of nurse staffing. Safety measures (mostly focusing on adverse events) dominate all other NSPOs; and quality of care is rarely examined. Some argue that this focus on safety is justified (Liu 2012), after all, one of a nurse's primary objectives is to keep their patients safe and prevent or at worst, minimise any harm occurring. It seems reasonable to argue however, that as NSPO research evolves and the measurement of the impact of nursing practice on patient outcomes is expanded and refined, it is time we, (that is all nurses) focused on the quality as well as the safety of care. A focus on quality of care indicators has increasingly been seen in recommendations from reports on health care failures (Francis 2013, Garling 2008) and standards (Australian Commission on Safety and Quality in Health Care 2010) and is mirrored in research around patient care experiences (McCance et al. 2016).

Research on what constitutes a good nurse has also been undertaken. From a nurses' perspective: personal characteristics (caring, being present, showing compassion and respect); professional characteristics (being patient-centred, respecting professional standards and codes); knowledge base (strong professional and situational knowledge, using critical thinking); and professional skills (demonstrating safe and competent care) are seen as important (Arman \& Rehbsfeldt 2007, Bassett 2002, Lynn \& McMillen 1999, Miller 2006, Smith \& Godfrey 2002). Patients, in contrast have differing views on what good quality nursing 
involves. They are more likely to care about the communication, kindness, listening and responsiveness of the nurses that are caring for them (Burhans \& Alligood 2010). These differing views make measurement of nursing practice even more complex. Given the differing views of these key stakeholders, it is appropriate to involve patients and nurses working in clinical practice settings in research to identify NSPO's.

To identify the most important concepts for measuring nursing practice, a four round modified Delphi study was conceptualised. This study sought to identify important concepts for measuring nursing practice, gain consensus of nurses on the importance of those concepts, and identify how those concepts could be conceptualised. This research is seen as important in being able to identify, conceptualise and eventually measure, the impact nursing care has on patient outcomes in a holistic and comprehensive way.

\section{METHOD}

\section{Design}

The Delphi technique is an iterative multi-stage process designed to combine the opinion of many individuals into consensus (McKenna 1994). The Delphi technique was chosen for the following reasons: 1) the research problem benefitted from subjective judgements on a collective basis; 2) the research population came from diverse backgrounds; 3) more subjects were needed than could effectively interact in interviews / meetings; 4) time, cost and logistics made frequent meetings of all subjects unfeasible; and 5) group conflict or domination needed to be prevented (Duffield 1993, McKenna 1994). 
In Round 1 key concepts were identified by patients and nurses via interviews. The subsequent three rounds used an online survey tool to examine the key concepts from Round 1, identify additional concepts, evaluate the importance of these concepts and confirm constructs developed from the important concepts. A maximum of four rounds was set prior to commencement of the project. This is consistent with approaches used by other researchers (Crisp et al. 1997, Hasson et al. 2000, Keeney et al. 2006, McKenna 1994).

\section{Participants}

Round 1 - qualitative interviews

Round 1 participants were either recipients of nursing care (patients) $(n=7)$ or Australian nurses who had published a peer-reviewed paper about nursing outcomes or nursing quality (Nurse authors) over the previous 10 years $(n=6)$. Patients were recruited via the Consumer Advisory Panel of two Local Health Districts within NSW, Australia. Nurse authors were identified via searches of electronic databases for relevant papers. A total of twelve potential participants were identified and invited to participate via an email introduction.

Rounds 2 to 4 - consensus building

Participants in Rounds 2-4 were nurses ( $R 2 n=196$; $R 3 n=169$; $R 4 n=128$ ) drawn from two Local Health Districts within NSW, Australia and a private sector healthcare organisation. These organisations were chosen due to their large size, the geographical spread of their services and to incorporate both public and private 
sector organisations. A sampling frame was used to target a broad range of different nursing roles and specialty areas which included inpatient and outpatient settings. Participants were recruited via promotional flyers, email communications or following information sessions conducted by the researcher at their workplace.

\section{Data collection and analysis}

Round 1 - qualitative interviews

The semi-structured interview schedules were developed following a comprehensive literature review (Authors own). The focus of the patient interviews was on understanding what quality nursing care is and how it is identified and valued by patients. The consumer group interviews aimed to answer the following research question: what are the key elements of quality nursing care from the perspective of patients / consumers? All participants were asked the same questions.

The focus of the nurse author interviews was on building knowledge regarding how nursing care can be measured. This included discussion about what nursingsensitive outcomes are; exploration of how nursing-sensitive outcomes are used; identification of conceptual frameworks that are used to identify and measure nursing-sensitive outcomes; and developing knowledge on specific nursing-sensitive outcomes and how data could be collected on them. Specifically the expert nurse interviews aimed to answer the following research questions: (1) what nursingsensitive outcomes are currently being used in Australia to measure the outcomes of nursing practice? (2) what conceptual frameworks are used to guide the measurement of nursing-sensitive outcomes in research and practice? (3) what concepts should be considered when measuring the outcomes of nursing practice? 
All interviews were conducted over a three month period. Each interview was digitally recorded and transcribed verbatim by one author (\#\#). Transcripts and accompanying field notes were reviewed and coding verified by two authors (\#\# and \#\#). The data were analysed using Braun and Clarke's (2006) thematic analysis framework. Thematic analysis is a method used for identifying, analysing and reporting patterns within qualitative data and has six phases (Braun \& Clarke 2006): 1) Familiarising yourself with your data; 2) Generating initial codes; 3) Searching for themes; 4) Reviewing themes; 5) Defining and naming themes; and 6) Producing the report.

A conscious decision was made to adopt Donabedian's (1966) framework of structure, process and outcome (SPO) measures to identify key concepts for the round 2 survey. Donabedian's SPO framework describes three categories for measuring the quality of care (Donabedian 1980). Structure relates to the attributes of the settings in which the care occurred (Donabedian 1980,1988). Process relates to what actually occurred in giving and receiving care (Donabedian 1980, 1988). Outcome relates to the changes that are observed in a patient or client's health and/or condition that result from the care that has been provided to them (Donabedian 1980, 1988).

Data from Round 1 was used to identify the key concepts to be measured in the round 2 survey. The key concepts were identified and clustered together using concept mapping techniques under each of the structure, process and outcome categories.

This article is protected by copyright. All rights reserved. 
Rounds 2 to 4 - consensus building

The fifty-six concepts identified in round 1 were used to develop the round 2 survey. The online survey was pilot tested with a convenience sample of 10 nurses from a local University. The pilot testing resulted in minor modifications to the wording of a few concepts to improve clarity.

The survey, delivered online via Survey Monkey software (Survey Monkey Inc 2011), was distributed to participants as a hyperlink within an individualised email. The use of individualised emails facilitated a structured reminder process, which included a maximum of three reminders to complete the survey over the two-week study period. Participants were asked to rank the importance of each concept for evaluating the outcomes of nursing practice on a five point Likert scale (where 1=very important and $5=$ totally unimportant). Consensus was defined as $75 \%$ of participants rating the concept as important (Likert scale 1 or 2). Qualitative fields allowed respondents to provide suggestions on additional concepts that should be considered.

Data were downloaded from Survey Monkey (Survey Monkey Inc 2011) into SPSS Version 17.0 (SPSS Inc 2008). Descriptive statistics were used to analyse the perceived level of importance of concepts. Qualitative data were imported into Microsoft Word and analysed using Braun and Clarke's (2006) phases of thematic analysis. The qualitative data was analysed to identify additional concepts for consideration in subsequent rounds (Hasson et al. 2000).

The round 3 survey was developed following analysis of the round 2 data and included any concepts that did not achieve consensus agreement in round 2; and additional concepts suggested by participants in qualitative data from the round 2 survey. Feedback was provided to all participants on the mean, standard deviation 
and level of consensus agreement for all statements within round 2. Analysis of the round 3 survey determined that 103 concepts had achieved consensus. Round 4 was then conducted to seek agreement on the grouping of the identified concepts into constructs. Using data from rounds 2 and 3, the research team themed the 103 concepts and similarly themed concepts were categorised together under broad constructs. Names were given to each construct based on data from the round 1 interviews where possible. A total of eight constructs were identified during this conceptual mapping process. During round 4 participants confirmed this analysis and grouping.

\section{Ethical considerations}

This study was approved by the \#\#\#\#\#\# (Approval No HEXX-XXXX). All participants volunteered to participate and received a participant information sheet explaining their rights and responsibilities and the voluntary nature of their involvement. All participants provided informed consent. All data was de-identified during data analysis and stored securely.

\section{RESULTS}

\section{Round 1}

Seven patients took part in qualitative interviews in Round 1. The patient interviews were conducted with individuals who responded to a promotional flyer and all were aged over 65 years. Two participants were male. All participants were either retired or no longer able to work full-time. All participants used English as their first 
language. Patients identified four key themes around what they perceived to be quality care, namely: Ask the patient if they feel 'cared for'!; feeling safe is complex; caring should be person-centred; and nursing knowledge is visible. Patients identified that they wanted to provide feedback on nursing care, as caring was seen to be a fundamental component of nursing care. All participants discussed the requirement to feel safe when in hospital but it was evident from these discussions that what it means to feel safe was complex and varied between participants. Patients also described in varying ways the concepts of person-centred caring. Patients discussed their experiences in hospital and used the following words to describe them: "lack of control"; "power imbalances"; "loss of usual home environment"; issues of identity; and "feeling involved" in their own care. All participants discussed how these experiences were enhanced when nurses communicated with them, involved them in decisions about their care and empowered them to take an active part in their healthcare. Participants also described how nursing knowledge is visible. One participant said:

You can actually see it [knowledge] in how they [nurses] go about things [pause] you can see in their hands how intelligent they are [pause] how they manage their work. (Patient Interview - Participant 6).

Six nurse authors agreed to participate in qualitative interviews in Round 1. Five of the six participants were female. All participants used English as their first language and all worked in academic positions within a University or in co-joint appointments between a health service and an academic organisation. The nurse authors raised four key themes around the measurement of nursing outcomes: safety is the first priority; positive measures are absent; methodological rigour is fundamentally important; and the visibility of nursing care. All nurse authors described the importance of measuring the safety outcomes of nursing care; for some measuring 
safety was the only focus of their research endeavours. Most nurse authors discussed how positive measures of nursing were absent from existing indicator sets. All nurse authors explored the need to ensure that nursing-sensitive outcome measures accurately and reliably measure the impact that nursing care has on patients/patient outcomes. The visibility of nursing care was discussed by some of the nurse authors. One nurse author described the work of nurses as invisible because the cognitive components of nursing work are frequently not documented or acknowledged. In contrast to this another nurse author described the visibility of nursing care and talked about the "panoptical role of nurses" in preventing adverse events and linked this with the concept of "failure to rescue". This participant also reflected on their own experiences as a recipient of nursing care:

I used to know if the nurse who arrived at my door was senior or junior and I used to describe it as the nursing gaze because they would stand at the door and if they were an experienced nurse they would do that sort of sweep of the room and they'd say, hi, l'm coming to take your blood pressure, but they'd walk forwards picking up this, moving that, lifting that, checking this, looking at that, fiddling with the other. If it were a junior nurse she would come in and stare at the blood pressure cuff on the wall and say, I am coming to take your blood pressure, and that's what she would do and then she would leave [pause] but by and large the more inexperienced they were the more task focused they were and the less safe you felt. (Nurse Author Interview - Participant 4).

At the completion of Round 1, Donabedian's (1980) framework of structure, process and outcomes was used to organise the data and identify individual concepts from the interview data. This process resulted in lists of key concepts that were then organised into structure, process and outcome categories under headings to group similar concepts together. The first draft of the conceptual framework was developed at the completion of Round 1 and is presented in Figure 1.

This article is protected by copyright. All rights reserved. 


\section{Round 2}

One hundred and ninety-six participants completed the round 2 survey. Most participants were female $(n=172,87.8 \%)$, were aged over 35 years $(n=169,86.2 \%)$, worked in the public healthcare system ( $n=165,84.2 \%)$, and had over 15 years nursing experience $(n=143,73.0 \%)$. The demographic characteristics of participants is summarised in Table 1.

Fifty-five of the 56 concepts achieved consensus agreement $(>75 \%)$ on their importance. Most concepts ( $n=45 ; 80.4 \%)$ achieved higher than $90 \%$ agreement on their importance and $4(7.1 \%)$ of these reached unanimous consensus. Only the item, 'number of referrals' failed to achieve consensus as important, with only 134 participants (68.4\%) rating this item as 'important'. The concepts examined in round 2 are listed in table 2 by percentage agreement on importance. The concepts are organised into the framework described in Figure 1.

Round 2 participants provided significant qualitative feedback and proposed an additional 52 new concepts for consideration in the subsequent round. The qualitative feedback was related to the following domains: 1) Structural measures; patient characteristics; nurse characteristics; organisational characteristics. 2) Process measures; patient perceptions; concepts related to the process of care. 3) Outcome measures; safety outcomes; patient perceptions / satisfaction; quality of care indicators. Using Braun and Clarke's (2006) thematic analysis framework, similar comments were grouped together and collapsed where possible. Unique statements were then identified. As a result of this analysis, 52 new concepts for inclusion in the round 3 survey were identified. 


\section{Round 3}

One hundred and sixty-nine round 2 participants completed the round 3 survey (response rate $86.2 \%$ ). The concept that did not achieve consensus agreement in round 2 was relabelled from 'number of referrals' to 'caseload' based upon participant feedback. With this change, 161 participants (95.3\%) rated the concept as important. Of the 52 new concepts presented in round 3, 47 concepts $(90.4 \%)$ achieved consensus agreement on their importance (Table 3). Two of these concepts achieved unanimous agreement on their importance, namely: leadership of unit; and communication processes within unit, (e.g. handover). Forty-one of these concepts (78.8\%) achieved higher than $90 \%$ agreement on their importance. Five of the concepts did not achieve consensus agreement, namely: patient's age (66.1\%); type of presentation (68.0\%); affiliation with research / academic unit $(71.4 \%)$; patient's cultural background and/or language spoken at home (73.2\%); and staff cultural and language background (74.0\%). The concepts examined in round 3 are listed in table 3 by percentage agreement on importance. The concepts are organised into the same framework described in Figure 1 and used in Round 2.

\section{Round 4}

One hundred and twenty-eight of the 169 round 3 survey participants participated in round 4 (response rate $75.7 \% ; 65.3 \%$ of original participants). Participants were presented with the eight constructs identified by the researchers and asked to indicate their agreement on whether concepts had been themed into appropriate constructs. Consensus was achieved for $97 \%(n=100)$ of the concepts being themed in an appropriate construct. Given that the majority of participants confirmed the 
constructs presented in the survey, no changes were made to the conceptual groupings.

At the completion of the Delphi technique, the researchers refined the conceptual framework for measuring the quality and safety outcomes of nursing practice. A visual representation of that framework which includes the constructs agreed in round 4 , is presented in Figure 2. This version of the framework builds on the framework presented in Figure 1 by conceptualising the process and outcome measures into the constructs of: care and caring; communication; coordination and collaboration; and safety.

\section{DISCUSSION}

In this study patients, nurse authors and clinical nurses were used to identify the important concepts on how nursing practice can be measured and obtain consensus agreement on their importance. Participants were from a broad range of geographic areas, nursing roles \& clinical specialty areas. The high response rate across all rounds demonstrates the participants' commitment to identifying appropriate concepts for measuring nursing practice; gaining consensus on the importance of those concepts; and identifying how those concepts could be conceptualised. Most participants $(73 \%)$ had in excess of 15 years' experience as a nurse and is confirmation of their expertise and ability to contribute to knowledge generated in this study.

This article is protected by copyright. All rights reserved. 
At the completion of four rounds of the modified Delphi technique, consensus had been achieved on 103 concepts seen as being important in measuring nursing practice. These 103 concepts were then organised into 8 constructs and agreement from participants on the constructs and conceptual groupings was achieved. Participants in this study identified a broad range of concepts that they deemed as important for measuring nursing practice within these 8 constructs. This is in contrast to what is seen in the literature in most NSPO research, as most indicator sets such as NDNQI (Press Ganey 2017) and CALNOC (2017) examine indicators related to patient safety as their primary focus. Indicators typically include concepts such as falls, pressure injuries and medication errors as well as measures of nurse staffing such as the quantity and attributes of the nursing staff including skill mix, educational preparation and hours of care. These indicators are included in the 103 concepts identified in this study, but the contrast between this research and existing datasets (such as NDNQI and CALNOC) comes when exploring the concepts of caring, communication and the coordination and collaborating roles of the nurse (which might be seen as indicators of quality). Some may argue that safety is the most important construct in healthcare, and it is indeed, very important. However, if the only component of nursing practice that is evaluated relates to safety then other components of the nursing role become devalued and nurses may cease to provide comprehensive care that is focused on the unique and varying requirements of each individual. This would have significant implications for nursing as a caring profession and for patient outcomes when the caring components of the nursing role and the need for high levels of communication to avert poor outcomes are seen in most health care enquiries (for example: Francis Report; Garling report; To Err is Human)(Francis 2013, Garling 2008, Institute of Medicine 2001) 
Some large scale research initiatives such as RN4CAST use patient experience data from tools such as HCAHPS (Aiken et al. 2016) to provide a broader context to NSPO research. Inclusion of patient reported outcomes is increasingly being seen as pivotal in evaluating nursing practice. The National Nursing Research Unit (NNRU) at King's College London (Maben et al. 2012) promoted this approach in 2012. The NNRU identified the need to link nursing quality measurement to patient experiences of care and suggested that patient experiences of dignity, respect, involvement in decision making and information provided to them about their treatment, should be examined as part of evaluating nursing practice (Maben et al. 2012). Including patient experiences within NSPO research is relatively new and has not been reported in existing indicator sets such as NDNQI and CALNOC (CALNOC 2017, Press Ganey 2017). The indicators identified in this study embrace the concept of person-centredness as a foundational element of high quality, safe nursing care (McCormack \& McCance 2017). Focusing on person-centredness is consistent with recommendations from a number of organisations and individuals (for example, Australian Commission on Safety and Quality in Health Care 2010, Berwick 2008, Institute of Medicine 2001) but has not been reported in NSPO research to date.

Similarly, most of the published conceptual frameworks which examine nursing outcomes have a primary focus on either safety outcomes or nurse staffing (Stone et al. 2007, Unruh 2008). Only, a small number have a broad focus on the quality and safety of nursing practice from the perspective of the person receiving nursing care. The most notable of these are: the Quality Health Outcomes Model (Mitchell et al. 1998); the Nursing Role Effectiveness Model (Doran et al. 2006); the ANA Nursing Report Card (Jones et al. 1997); the AHRQ Nurse staffing and quality of patient care 
(Hughes 2008); the Outcomes Assessment Tool for Acute Care (Cranley \& Doran 2004); and the Nurse staffing, Quality of care and Outcomes conceptual framework (Clarke \& Donaldson 2008). The conceptual framework developed within this project expands on these previous approaches in the following ways. Firstly, it categorises nursing care into constructs that describe the actions of nurses which relate directly to the work that nurses undertake within their clinical practice. Examination of these constructs enables conceptualisation and measurement of the work nurses do. Secondly, this conceptual framework has used a person-centred lens to develop and conceptualise the framework (McCormack \& McCance 2006). This means that it seeks to examine indicators and outcomes that relate to the person receiving nursing care. Thirdly, the conceptual framework uses language that the recipients of nursing care can understand and interpret. This was a deliberate decision to ensure that the nomenclature used to describe nursing could be understood by the recipients of nursing care, the healthcare team, all nurses and the general public. Finally, this conceptual framework explicitly uses structure, process and outcome measures (Donabedian 1988) to ensure that the link can be made between what nurses do and the outcomes they achieve.

\section{Limitations}

In Round 1, there were a number of limitations related to sampling. All patient participants responded to a promotional flyer and as a result were self-selected. Selfselection may have resulted in some degree of bias due to a person's desire and willingness to participate. The consensus rounds within this study involved a purposeful sample of clinical nurses in a single region of New South Wales, 
Australia. While the sample was large when compared to other Delphi surveys, care needs to be taken when transferring findings to other health services. International comparison would need to consider the health care system and the role of nurses in their context. Another limitation of this research is that it has not identified how data from the 103 concepts identified in this project would be collected or whether it is feasible to measure nursing practice from the 8 domains identified in the conceptual framework. These will need to be tested in future research.

\section{CONCLUSION}

Consensus was achieved by nurses on the most important concepts which can provide the basis for measuring the quality and safety of nursing practice. These concepts examine patient outcomes that occur as a result of nursing care in a holistic and comprehensive way and can be used to develop indicators of nursing practice. This research provides a conceptual framework that can be used by nurses, units and hospitals to explore the important constructs in nursing practice and provides guidance on the important concepts that can be used to examine the quality and safety outcomes of nursing care. Further testing is required to determine how the concepts identified within this study can be measured and the feasibility and efficacy of such a tool.

\section{RELEVANCE TO CLINICAL PRACTICE}

The findings of this study demonstrate that nurses want more than the safety outcomes to be used to evaluate their practice. Traditional NSPO's such as falls, pressure injuries and medication errors were identified by participants in this study. 
However, patient experiences and the characteristics of the working environment achieved close to $100 \%$ agreement on importance by participants. The concepts of providing care and being caring, effective communication and the important skills of coordination \& collaboration of the care experience were all recognised as pivotal to measuring the outcomes of nursing practice. Reliable and feasible ways of examining these concepts must now be identified so that both the safety and the quality of nursing practice can be evaluated.

\section{REFERENCES}

Aiken LH, Sloane D, Griffiths P, Rafferty AM, Bruyneel L, McHugh M, Maier CB, Moreno-Casbas T, Ball JE, Ausserhofer D \& Sermeus W (2016) Nursing skill mix in European hospitals: cross-sectional study of the association with mortality, patient ratings, and quality of care. BMJ Quality \& Safety in press, 1-10. doi: 10.1136/bmjqs2016-005567

Arman M \& Rehbsfeldt A (2007) The 'Little Extra' that alleviates suffering. Nursing Ethics 14, 372-386.

Australian Commission on Safety and Quality in Health Care (2010) Patient-Centred care: Improving quality and safety by focusing care on patients and consumers. Australian Commission on Safety and Quality in Health Care, Sydney.

Authors own (2015). Withheld for peer review

Authors own (2017). Withheld for peer review

Bassett C (2002) Nurses' perceptions of care and caring. International Journal of Nursing Practice 8, 8-15.

Berwick D (2008) The Science of Improvement. JAMA 299, 1182-1184.

Braun V \& Clarke V (2006) Using thematic analysis in psychology. Qualitative Research in Psychology 3, 77-101.

Burhans LM \& Alligood MR (2010) Quality nursing care in the words of nurses. Journal of Advanced Nursing 66, 1689-1697.

CALNOC (2017) CALNOC History. Available at: http://www.calnoc.org/?page=6 (accessed 24 February 2017).

Clarke SP (2009) Three metaphors and a (mis)quote: thinking about staffingoutcomes research, health policy and the future of nursing. Journal of Nursing Management 17, 151-154.

Clarke SP \& Donaldson N (2008) Nurse staffing and patient care quality and safety. In Patient safety and quality: An evidence-based handbook for nurses (Hughes $\mathrm{R}$ 
Ed.). Agency for Healthcare Research and Quality, Rockville, MD, pp. 2/111-135.

Cranley L \& Doran D (2004) Nurses' integration of outcomes assessment data into practice. Outcomes Management 8, 13-18.

Crisp J, Pelletier D, Duffield C, Adams A \& Nagy S (1997) The Delphi method? Nursing Research 46, 116-118.

Donabedian (1966) Evaluating the quality of medical care. The Millbank Memorial Fund Quarterly 44, 166-206.

Donabedian A (1980) The definition of quality and approaches to its assessment. Health Administrtaion Press, Ann Arbor, MI.

Donabedian A (1988) The Quality of Care: How can it be assessed? Journal of American Medical Association 260, 1743-1748.

Doran D (2003) Nursing-Sensitive Outcomes: State of the Science. Jones \& Bartlett Publishers, Sudbury, Massachusetts.

Doran D, Harrison MB, Laschinger H \& Hirdes J (2006) Relationship between nursing interventions and outcome achievement in acute care settings. Research in Nursing \& Health 29, 61-61-70.

Duffield C (1993) The Delphi technique: a comparison of results obtained using two expert panels. International Journal of Nursing Studies 30, 227-237.

Francis R (2013) Report of the Mid Staffordshire NHS Foundation Trust Public Inquiry 3 Volumes, London. Available at:

http://webarchive.nationalarchives.gov.uk/20150407084003/http://www.midstaffspubl icinquiry.com/report (accessed 7th March 2017).

Garling P (2008) Final Report of the Special Commission of Inquiry: Acute Care Services in NSW Public Hospitals, Sydney. Available at:

http://www.dpc.nsw.gov.au/?a=34194 (accessed 7th March 2017).

Griffiths P, Ball J, Murrells T, Jones S \& Rafferty AM (2016) Registered nurse, healthcare support worker, medical staffing levels and mortality in English hospital trusts: a cross-sectional study. BMJ Open 6, 1-7.

Hasson F, Keeney S \& McKenna H (2000) Research guidelines for the Delphi survey technique. Journal of Advanced Nursing 32, 1008-1015.

Hughes R (2008) Patient Safety and Quality: An evidence-based handbook for nurses. Agency for Healthcare Research and Quality, Rockville, MD.

Institute of Medicine (2001) To Err is Human: Building a Safer Health System (Committee on Quality of Health Care in America ed.). National Academy of Sciences, Washington D.C.

International Council of Nurses (ICN) (2009) Nursing matters factsheet: Nursing sensitive outcome indicators. Available at:

http://www.icn.ch/images/stories/documents/publications/fact_sheets/15c_FSNursing_Sensitive_Outcome_Indicators.pdf (accessed 25th February 2017).

Jones K, Jennings B, Moritz P \& Moss M (1997) Policy issues associated with analyzing outcomes of care. Journal of Nursing Scholarship 29, 261-267.

Keeney S, Hasson F \& McKenna H (2006) Consulting the oracle: ten lessons from using the Delphi technique in nursing research. Journal of Advanced Nursing 53, 
205-212.

Kurtzman ET \& Corrigan JM (2007) Measuring the contribution of nursing to quality, patient safety, and health care outcomes. Policy, Politics \& Nursing Practice 8, 20-

25.

Liu L-F (2012) Exploring the Association Between Nurse Workload and NurseSensitive Patient Safety Outcome Indicators. The journal of nursing research 20 , 300-309.

Lynn M \& McMillen B (1999) Do nurses know what patients think is important in nursing care? Journal of Nursing Care Quality 13, 65-74.

Maas ML, Johnson M \& Moorhead S (1996) Classifying nursing-sensitive patient outcomes. Image: Journal of Nursing Scholarship 28, 295-301.

Maben J, Morrow E, Ball J, Robert G \& Griffiths P (2012) High Quality Care Metrics for Nursing. National Nursing Research Unit, King's College London.

Marek K (1998) Measuring the effectiveness of nursing care. Outcomes Management for Nursing Practice 1, 8-12.

McCance T, Wilson V \& Kornman K (2016) Paediatric International Nursing Study: using person-centred key performance indicators to benchmark children's services. Journal of Clinical Nursing 25, 2018-2017.

McCormack B \& McCance T (2017) Person-centred practice in Nursing and Health Care: Theory and practice, 2nd edn. John Wiley \& Sons Ltd, Chichester, West Sussex.

McCormack B \& McCance TV (2006) Development of a framework for personcentred nursing. Journal of Advanced Nursing 56, 472-472.

McKenna H (1994) The Delphi technique: a worthwhile approach for nursing? Journal of Advanced Nursing 19, 1221-1225.

Miller J (2006) Opportunities and obstacles for good work in nursing. Nursing Ethics 13, 471-487.

Mitchell PH, Ferketich S \& Jennings B (1998) Quality Health Outcomes Model. Image: Journal of Nursing Scholarship 30, 43-46.

Needleman J, Buerhaus P, Mattke S, Stewart M \& Zelevinsky K (2002) Nurse staffing and quality of care in Hospitals in the United States. Policy, Politics \& Nursing Practice 3, 306-308.

Press Ganey (2017) Nursing Quality (NDNQI). Available at:

http://www.pressganey.com/solutions/clinical-quality/nursing-quality (accessed 24 February 2017).

Sermeus W, Aiken L, Van den Heede K, Rafferty AM, Griffiths P, Moreno-Casbas M, Busse R, Lindqvist R, Scott A, Bruyneel L, Brzostek T, Kinnunen J, Schubert M, Schoonhoven L, Zikos D \& RN4CAST Consortium (2011) Nurse forecasting in Europe (RN4CAST): Rationale, design and methodology. BMC Nursing 10, 1-9.

Smith K \& Godfrey N (2002) Being a good nurse and doing the right thing: a qualitative study. Nursing Ethics 9, 301-312.

SPSS Inc (2008) SPSS Statistics for Windows, Version 17.0. SPSS Inc, Chicago, USA.

This article is protected by copyright. All rights reserved. 
Stone PW, Mooney-Kane C, Larson EL, Horan T, Glance LG, Zwanziger J \& Dick AW (2007) Nurse working conditions and patient safety outcomes. Medical Care 45, 571-578.

Survey Monkey Inc (2011) Survey Monkey. San Mateo, California, USA.

Twigg D, Pugh J, Gelder L \& Myers H (2016) Foundations of a nursing-sensitive outcome indicator suite for monitoring public patient safety in Western Australia. Collegian 23, 167-181.

Unruh L (2008) Nurse staffing and patient, nurse, and financial outcomes. American Journal of Nursing 108, 62-72.

Unruh LY \& Zhang NJ (2012) Nurse Staffing and Patient Safety in Hospitals: New Variable and Longitudinal Approaches. Nursing Research 61, 3-12.
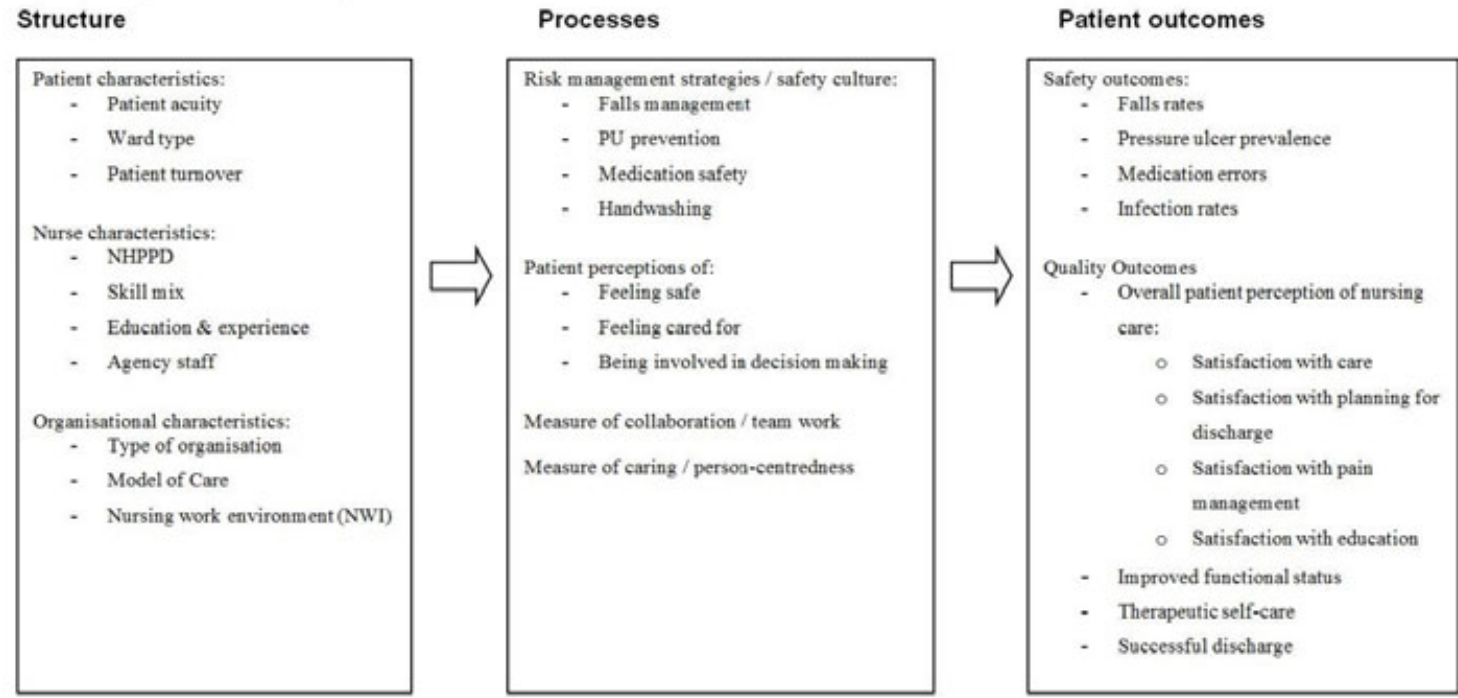

Figure 1: Summary of concepts identified in Round 1

This article is protected by copyright. All rights reserved. 
Table 1: Characteristics of Round 2 participants

\begin{tabular}{|c|c|c|}
\hline \multicolumn{3}{|l|}{ Sex } \\
\hline Male & 23 & 11.7 \\
\hline Female & 172 & 87.8 \\
\hline No answer & 1 & 0.5 \\
\hline \multicolumn{3}{|l|}{ Type of organisation } \\
\hline Public & 165 & 84.2 \\
\hline Private & 31 & 15.8 \\
\hline \multicolumn{3}{|l|}{ Role } \\
\hline AIN (Assistant in Nursing) & 2 & 1.0 \\
\hline EN / EEN (Enrolled Nurse / Endorsed Enrolled Nurse) & 6 & 3.1 \\
\hline RN (Registered Nurse) & 48 & 24.5 \\
\hline $\begin{array}{l}\text { CNS (Clinical Nurse Specialist) / CNC (Clinical Nurse } \\
\text { Consultant) }\end{array}$ & 62 & 231.6 \\
\hline CNE (Clinical Nurse Educator) / NE (Nurse Educator) & 20 & 10.2 \\
\hline NUM (Nurse Unit Manager) / NM (Nurse Manager) & 58 & 29.7 \\
\hline \multicolumn{3}{|l|}{ Age } \\
\hline $18-24$ & 8 & 4.1 \\
\hline $25-34$ & 19 & 9.7 \\
\hline $35-44$ & 44 & 22.4 \\
\hline $45-54$ & 78 & 39.8 \\
\hline $55-65$ & 46 & 23.5 \\
\hline Over 65 & 1 & 0.5 \\
\hline \multicolumn{3}{|l|}{ Years of nursing experience } \\
\hline $0-5$ & 17 & 8.7 \\
\hline $6-14$ & 36 & 18.4 \\
\hline $15-24$ & 47 & 24.0 \\
\hline Over 25 & 96 & 49.0 \\
\hline
\end{tabular}

This article is protected by copyright. All rights reserved. 
Table 2: Round 2 Agreement on importance

\begin{tabular}{|c|c|c|c|}
\hline Item & $\begin{array}{c}\text { Level of } \\
\text { agreement on } \\
\text { importance }(\%)\end{array}$ & Mean & $\begin{array}{c}\text { Std. } \\
\text { Deviation }\end{array}$ \\
\hline \multicolumn{4}{|l|}{ Structural measures: Patient characteristics } \\
\hline Patient acuity & 98.0 & 1.28 & 0.51 \\
\hline Diagnosis Related Group (DRG) & 83.7 & 1.80 & 0.76 \\
\hline Patient turnover & 83.1 & 1.88 & 0.84 \\
\hline Ward / department type & 82.0 & 1.90 & 0.76 \\
\hline Casemix information & 79.6 & 1.95 & 0.77 \\
\hline \multicolumn{4}{|l|}{ Structural measures: Nurse characteristics } \\
\hline Skill mix of nursing staff & 99.5 & 1.16 & 0.38 \\
\hline Education of nursing staff & 99.5 & 1.28 & 0.46 \\
\hline Experience of nursing staff & 99.0 & 1.27 & 0.47 \\
\hline Hours of available nursing care & 98.5 & 1.27 & 0.53 \\
\hline Number of casual staff & 84.0 & 1.74 & 0.78 \\
\hline Number of agency staff & 76.2 & 1.95 & 1.12 \\
\hline Number of referrals & 68.4 & 2.19 & 0.92 \\
\hline \multicolumn{4}{|l|}{ Structural measures: Organisational characteristics } \\
\hline Management support & 99.5 & 1.20 & 0.44 \\
\hline Nursing work environment & 97.9 & 1.33 & 0.51 \\
\hline Relationships with nursing colleagues & 97.9 & 1.35 & 0.59 \\
\hline Relationships with other health professionals & 97.4 & 1.42 & 0.55 \\
\hline Model of care in use & 89.7 & 1.65 & 0.66 \\
\hline Type of organisation & 76.7 & 1.99 & 0.69 \\
\hline \multicolumn{4}{|l|}{ Process measures: Patient/client perceptions } \\
\hline Patient/client perceptions of feeling 'safe' & 100 & 1.16 & 0.37 \\
\hline $\begin{array}{l}\text { Patient/client perceptions of being involved in } \\
\text { decision making }\end{array}$ & 100 & 1.25 & 0.43 \\
\hline Patient/client perceptions of feeling 'cared for' & 99.0 & 1.19 & 0.42 \\
\hline Patient/client perceptions of care & 99.0 & 1.31 & 0.51 \\
\hline
\end{tabular}

This article is protected by copyright. All rights reserved. 


\begin{tabular}{|c|c|c|c|}
\hline Presence of caring attitudes and actions & 100 & 1.18 & 0.39 \\
\hline $\begin{array}{l}\text { Presence of collaboration between healthcare } \\
\text { professionals }\end{array}$ & 100 & 1.35 & 0.48 \\
\hline Processes for safe administration of medications & 99.5 & 1.19 & 0.47 \\
\hline Presence of teamwork & 99.5 & 1.21 & 0.42 \\
\hline Presence of a safety culture & 99.0 & 1.35 & 0.50 \\
\hline Hand hygiene practices & 98.5 & 1.22 & 0.45 \\
\hline A person centred approach to care & 98.4 & 1.20 & 0.44 \\
\hline Falls prevention strategies & 97.9 & 1.42 & 0.58 \\
\hline Pressure ulcer prevention strategies & 95.9 & 1.45 & 0.69 \\
\hline Risk management strategies & 95.9 & 1.47 & 0.60 \\
\hline \multicolumn{4}{|l|}{ Outcome measures: Safety outcomes } \\
\hline Medication errors & 99.0 & 1.17 & 0.40 \\
\hline Hospital acquired infections & 96.4 & 1.33 & 0.59 \\
\hline Pressure ulcer prevalence & 95.8 & 1.57 & 0.65 \\
\hline Hospital acquired pressure ulcers & 95.3 & 1.38 & 0.65 \\
\hline Number of falls with injury & 95.3 & 1.46 & 0.6 \\
\hline Number of patient / client falls & 94.8 & 1.56 & 0.59 \\
\hline Central line associated blood stream infections & 93.2 & 1.38 & 0.73 \\
\hline Peripheral IV associated blood stream infections & 93.2 & 1.38 & 0.72 \\
\hline Failure to rescue & 89.1 & 1.57 & 0.80 \\
\hline Mortality rates & 87.5 & 1.69 & 0.81 \\
\hline \multicolumn{4}{|c|}{ Outcome measures: Patient/client perceptions or satisfaction } \\
\hline Patient/client satisfaction with pain management & 98.4 & 1.24 & 0.46 \\
\hline Overall satisfaction with nursing care & 97.9 & 1.42 & 0.58 \\
\hline $\begin{array}{l}\text { Patient/client satisfaction with individual focus of } \\
\text { care }\end{array}$ & 97.9 & 1.43 & 0.54 \\
\hline Patient/client perceptions of nursing care & 97.4 & 1.42 & 0.59 \\
\hline $\begin{array}{l}\text { Patient/client satisfaction with education from } \\
\text { nurses }\end{array}$ & 97.4 & 1.46 & 0.60 \\
\hline $\begin{array}{c}\text { Patient/client } \\
\text { discharge }\end{array}$ & 96.9 & 1.52 & 0.65 \\
\hline
\end{tabular}

This article is protected by copyright. All rights reserved. 


\begin{tabular}{|l|c|c|c|}
\hline Reduction / relief of symptoms & 98.4 & 1.28 & 0.48 \\
\hline Improved quality of life & 98.4 & 1.34 & 0.51 \\
\hline $\begin{array}{l}\text { Timely and successful referral to other health } \\
\text { professionals }\end{array}$ & 98.4 & 1.40 & 0.52 \\
\hline $\begin{array}{l}\text { Patient/client participation in self-care } \\
\quad \begin{array}{l}\text { Chronic disease management strategies in place } \\
\text { and understood }\end{array}\end{array}$ & 98.4 & 1.44 & 0.53 \\
\hline $\begin{array}{l}\text { Patient understanding of disease process } \\
\text { Improvements to functional status }\end{array}$ & 97.4 & 1.55 & 0.54 \\
\hline Successful discharge & 95.3 & 1.56 & 0.58 \\
\hline
\end{tabular}

Table 3: Round 3 Agreement on importance

\begin{tabular}{|c|c|c|c|}
\hline Item & $\begin{array}{l}\text { Level of agreement on } \\
\text { importance (\%) }\end{array}$ & Mean & $\begin{array}{c}\text { Std. } \\
\text { Deviation }\end{array}$ \\
\hline \multicolumn{4}{|l|}{ Structural measures: Patient characteristics } \\
\hline Patient's willingness to participate in care & 98.8 & 1.46 & 0.58 \\
\hline Cognitive status of patient & 95.9 & 1.47 & 0.65 \\
\hline $\begin{array}{l}\text { Pre-admission level of independence / } \\
\text { dependence }\end{array}$ & 95.9 & 1.52 & 0.60 \\
\hline Pre-admission quality of life & 92.9 & 1.65 & 0.67 \\
\hline $\begin{array}{l}\text { Patient expectations regarding healthcare } \\
\text { intervention }\end{array}$ & 92.9 & 1.67 & 0.71 \\
\hline Family involvement in care & 91.7 & 1.72 & 0.68 \\
\hline $\begin{array}{l}\text { Patient's cultural background and/or language } \\
\text { spoken at home }\end{array}$ & 73.2 & 2.08 & 0.89 \\
\hline Presentation to hospital e.g. emergency, elective & 68.0 & 2.14 & 0.87 \\
\hline Patient's age & 66.1 & 2.13 & 0.90 \\
\hline \multicolumn{4}{|l|}{ Structural measures: Nurse characteristics } \\
\hline Leadership of unit & 100 & 1.16 & 0.37 \\
\hline Competency of staff & 98.2 & 1.20 & 0.47 \\
\hline Nurse to patient ratio & 98.2 & 1.21 & 0.5 \\
\hline
\end{tabular}

This article is protected by copyright. All rights reserved. 


\begin{tabular}{|c|c|c|c|}
\hline Nursing culture & 98.2 & 1.32 & 0.51 \\
\hline Well-being of nursing staff & 97.6 & 1.29 & 0.51 \\
\hline Caseload & 95.3 & 1.41 & 0.60 \\
\hline Staff turnover (e.g. resignations and recruitment) & 93.5 & 1.57 & 0.63 \\
\hline Nursing overtime worked & 89.9 & 1.59 & 0.72 \\
\hline Physical fitness of nursing staff & 82.8 & 1.96 & 0.66 \\
\hline Staff cultural and language background & 74.0 & 2.03 & 0.83 \\
\hline \multicolumn{4}{|l|}{ Structural measures: Organisational characteristics } \\
\hline $\begin{array}{l}\text { Organisational commitment to providing best } \\
\text { practice }\end{array}$ & 98.8 & 1.29 & 0.48 \\
\hline $\begin{array}{l}\text { Organisational commitment to providing person- } \\
\text { centred care }\end{array}$ & 97.0 & 1.39 & 0.55 \\
\hline Organisational culture & 97.0 & 1.45 & 0.56 \\
\hline $\begin{array}{l}\text { Utilisation of evidence based practice within } \\
\text { organisation }\end{array}$ & 96.4 & 1.44 & 0.59 \\
\hline $\begin{array}{l}\text { Presence / availability of members of the } \\
\text { multidisciplinary team }\end{array}$ & 95.8 & 1.44 & 0.58 \\
\hline Management experience and qualifications & 94.6 & 1.55 & 0.62 \\
\hline $\begin{array}{l}\text { Presence / availability of after-hours education } \\
\text { and support }\end{array}$ & 92.9 & 1.69 & 0.64 \\
\hline Presence / availability of auxiliary staff in unit & 88.0 & 1.84 & 0.63 \\
\hline Affiliation with research / academic unit & 71.4 & 2.10 & .731 \\
\hline \multicolumn{4}{|l|}{ Process measures: Patient perceptions } \\
\hline Patient perceptions of 'being heard' & 99.4 & 1.25 & 0.45 \\
\hline $\begin{array}{l}\text { Patient perception of 'being informed' about } \\
\text { nursing care }\end{array}$ & 99.4 & 1.26 & 0.45 \\
\hline $\begin{array}{l}\text { Patient perceptions of communication with } \\
\text { nurses }\end{array}$ & 99.4 & 1.31 & 0.48 \\
\hline $\begin{array}{l}\text { Family perception of being involved in decision } \\
\text { making (where relevant) }\end{array}$ & 98.9 & 1.44 & 0.58 \\
\hline Patient perception of trust in nurses & 98.2 & 1.28 & 0.49 \\
\hline $\begin{array}{l}\text { Patient perception that care is appropriate / best } \\
\text { practice }\end{array}$ & 95.2 & 1.47 & 0.59 \\
\hline \multicolumn{4}{|c|}{ Process measures: Concepts related to the process of care } \\
\hline $\begin{array}{c}\text { Communication processes within unit (e.g. } \\
\text { handover) }\end{array}$ & 100 & 1.18 & 0.39 \\
\hline
\end{tabular}

This article is protected by copyright. All rights reserved. 


\begin{tabular}{|c|c|c|c|}
\hline $\begin{array}{l}\text { Documentation of nursing care within medical } \\
\text { record }\end{array}$ & 98.8 & 1.26 & 0.49 \\
\hline $\begin{array}{l}\text { Documentation of a comprehensive physical and } \\
\text { mental health assessment }\end{array}$ & 98.8 & 1.37 & 0.57 \\
\hline Continuity of care provided to patient & 98.8 & 1.39 & 0.51 \\
\hline $\begin{array}{l}\text { Documentation of nursing assessment within } \\
\text { medical record }\end{array}$ & 98.2 & 1.28 & 0.49 \\
\hline Delirium prevention strategies & 93.4 & 1.62 & 0.66 \\
\hline \multicolumn{4}{|c|}{ Outcome measures: Safety outcomes / Quality of care indicators } \\
\hline Patient education about discharge medications & 97.0 & 1.36 & 0.56 \\
\hline Number of clinical incidents / near misses & 95.2 & 1.46 & 0.59 \\
\hline Incidence of self-harm post admission & 88.7 & 1.68 & 0.69 \\
\hline Incidence of delirium post admission & 88.1 & 1.73 & 0.68 \\
\hline Unplanned readmissions & 85.6 & 1.74 & 0.73 \\
\hline Length of stay & 79.8 & 2.00 & 0.80 \\
\hline \multicolumn{4}{|l|}{ Outcome measures: Patient perceptions / satisfaction } \\
\hline $\begin{array}{l}\text { Patient satisfaction related to communication } \\
\text { with nurses }\end{array}$ & 98.8 & 1.43 & 0.58 \\
\hline $\begin{array}{l}\text { Family satisfaction with information provided by } \\
\text { nursing staff (where relevant) }\end{array}$ & 97.6 & 1.53 & 0.57 \\
\hline $\begin{array}{l}\text { Patient perception of whether their expectations } \\
\text { of their healthcare intervention have been met }\end{array}$ & 97.6 & 1.55 & 0.55 \\
\hline $\begin{array}{l}\text { Family satisfaction with involvement in care } \\
\text { (where relevant) }\end{array}$ & 97.6 & 1.55 & 0.60 \\
\hline $\begin{array}{l}\text { Patient satisfaction with management of } \\
\text { incidents and / or complaints }\end{array}$ & 97.0 & 1.46 & 0.58 \\
\hline $\begin{array}{l}\text { Patient satisfaction with support provided to } \\
\text { family / carers }\end{array}$ & 95.8 & 1.58 & 0.62 \\
\hline $\begin{array}{l}\text { Patient satisfaction with cultural awareness of } \\
\text { nursing staff }\end{array}$ & 94.0 & 1.70 & 0.68 \\
\hline
\end{tabular}

This article is protected by copyright. All rights reserved. 
Nursing-sensitive patient outcomes|

Structure

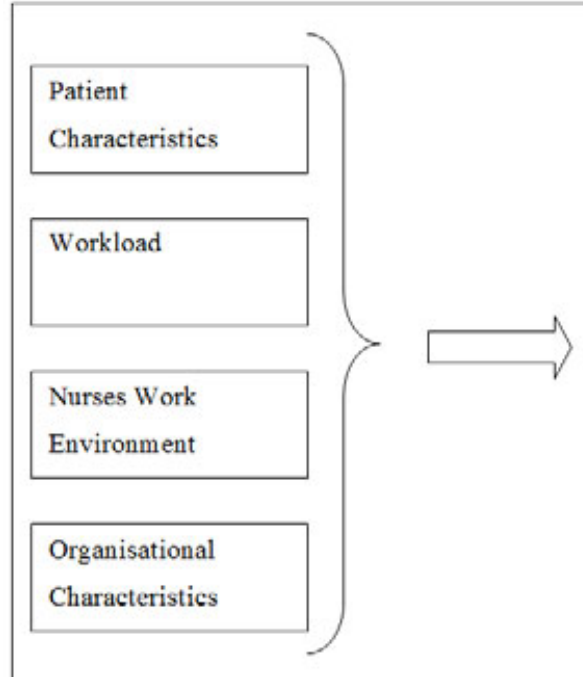

Processes + Patient Outcomes

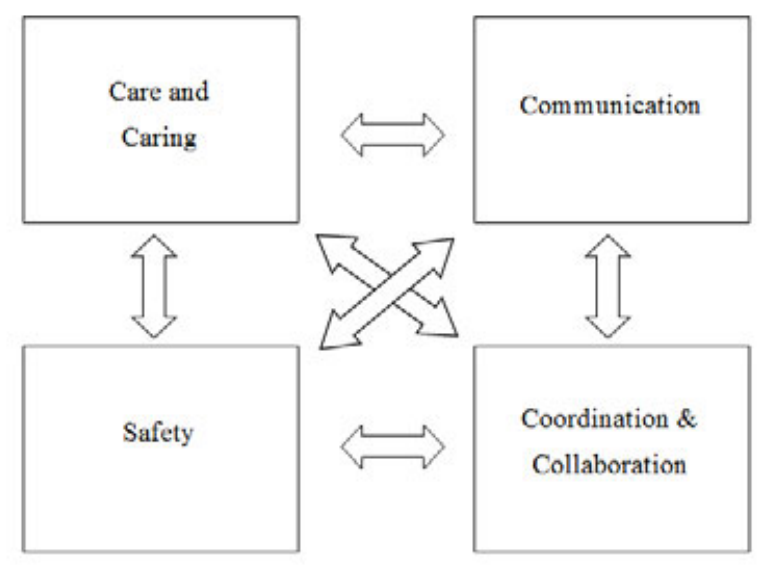

Figure 2: A conceptual framework for measuring the quality and safety outcomes of nursing practice.

This article is protected by copyright. All rights reserved. 